\title{
Influence of the Soil Conditions on the Sprout-growth of Tubers and Tuberous Roots \\ TOKUTARO INDEN \\ Summary
}

1. The investigations were carried out about the influences of the soil moisture and soil density on the germination of tubers and tuberous root of potato, taro, and Iseimo (one species of Chinese yam), and about the relation of the oxygen and carbon dioxide in the soil atmosphere to the germination of potatoes.

2. With the porous soil the suitable soil moisture for germination of tubers and tuberous roots is $60 \%$ of water capacity, but in the case of the dense soil it is $40 \%$.

Increasing soil moisture over these optimum levels, the normal respiration of tubers and tuberous roots are more or less disturbed owing to the decrease of the air content and air permeability in the soil.

When the air content decreases below $30 \%$, the velocity of the sprout growth of the tubers and tuberous roots declines.

3. A sufficient quantity of oxygen must be supplied for the germination of tubers and tuberous" roois.

As to potatoes, under low oxygen supply with in $4-12 \%$ of soil atmosphere, the bud and root growih and development do not reach $30 \%$ and root weight is only $13 \sim 14 \%$, of those under sufficient oxygen supply, such as $16 \sim 18 \%$ of soil atmosphere.

\section{市ギ及びタマネギの自家受精力について 建部圼雄}

T. TATEBE : Self-fertility in Allium fistulosum L and A. Cepo L.

\section{緒言}

ネギは一般に自家和合植物とみなされているが，タ、

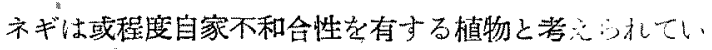
るよ5である。筑際ターネギの花序を被货し，外力口度

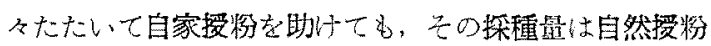
の場合に比し非賞に少い。ところが從来內外共に，名 ネギは自家和合植物であるいり報告が如るのてこの

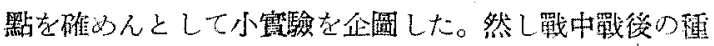

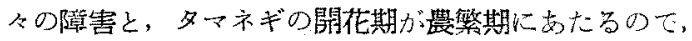

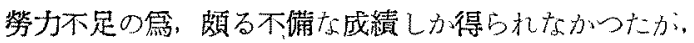

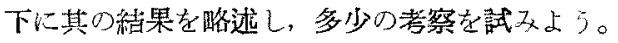

\section{材料及び方法}

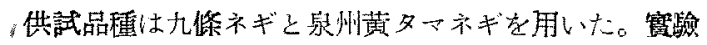
はネギの場合は露地て，ターネギか1944呚び1946の雨 年は确子空內で, 1948 年は政地のト夕ン板の屋根のだて

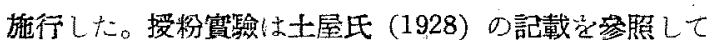
トのように管施した。ネギ皮びタマネギ共に雄赫先熟花 で女るから，豫めパラフィン紙の装をか外て置いた花序 につき，ほほ開花3日後，花杜が可なり伸び，又䒬が大 部分花粉を头つた買に授数を行つた。郎ち自家授粉に於

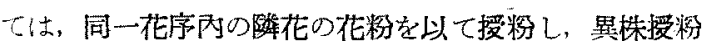

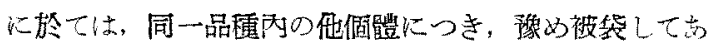
つた花の花粉を以て授粉した。其に除雄は行わなら口 た。文自然授粉區は放任して自然の授粉にまかせた。份 何机电一花序につき開花始めと終りの花は除去した。

\section{䨘驗成緗}

\section{1) $\approx \neq$}

1943 年收び 1946 年の成糞は第 1 表の通りで台つた。

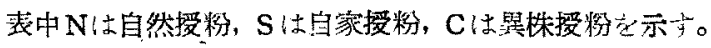

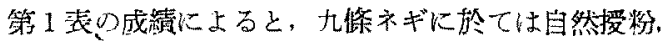

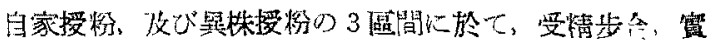




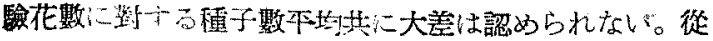
つて九條市ギは，從來上り考方られている通り，自家和 合植物と府ぜりる。

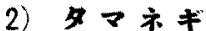

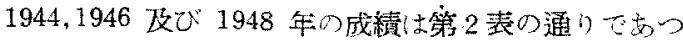
た。

很 1 表 キギの白家受精力

\begin{tabular}{|c|c|c|c|c|c|c|c|c|}
\hline 年次 & $\begin{array}{l}\text { 伨能 } \\
\text { 番號 }\end{array}$ & $\begin{array}{l}\text { 授粉 } \\
\text { 法 }\end{array}$ & $\begin{array}{l}\text { 簧驗 } \\
\text { 花數 }\end{array}$ & $\begin{array}{l}\text { 受㱔 } \\
\text { 花㛺 }\end{array}$ & $\begin{array}{l}\text { 妥精 } \\
\text { 步合 } \\
(0) \\
\end{array}$ & 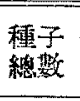 & 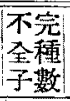 & 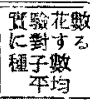 \\
\hline \multirow{15}{*}{1943} & \multirow{3}{*}{1} & $\mathrm{~N}$ & 129 & 127 & 98.45 & 705 & 15 & 5.47 \\
\hline & & $\mathrm{S}$ & 114 & 109 & 95.61 & 579 & 15 & 5.08 \\
\hline & & $\mathrm{C}$ & 97 & 89 & 91.75 & 430 & 7 & 4.33 \\
\hline & \multirow{3}{*}{2} & $\mathrm{~N}$ & 196 & 184 & 93.87 & 964 & 35 & 4.92 \\
\hline & & $\mathrm{S}$ & 97 & 91 & 93.81 & 461 & 21 & 4.75 \\
\hline & & $\vec{C}$ & 121 & 108 & 89.25 & 570 & 33 & 4.71 \\
\hline & \multirow{3}{*}{3} & $N$ & 212 & 207 & 97.64 & 1155 & 60 & 5.45 \\
\hline & & $\mathrm{S}$ & 137 & 125 & 91.24 & 701 & 45 & 5.11 \\
\hline & & $\mathrm{C}$ & 120 & 113 & 94.16 & 592 & 16 & 4.93 \\
\hline & \multirow{3}{*}{4} & $N$ & 164 & 149 & 90.85 & 648 & 15 & 3.95 \\
\hline & & $S$ & 118 & 106 & 89.83 & 455 & 10 & 3. 86 \\
\hline & & $\mathrm{C}$ & 122 & 106 & 86.88 & 428 & 4 & 3.51 \\
\hline & \multirow{3}{*}{5} & $N$ & 143 & $142^{-}$ & 99.30 & 662 & 25 & 4.63 \\
\hline & & $\mathrm{S}$ & 92 & 88 & 95.65 & 419 & 3 & 4.55 \\
\hline & & C & 103 & 100 & 97.08 & 513 & 4 & 4.98 \\
\hline \multirow{14}{*}{1916} & \multirow{2}{*}{1} & $\mathrm{~N}$ & 209 & 199 & 95.22 & 911 & 14 & 4.36 \\
\hline & & $\mathrm{S}$ & 187 & 183 & 97.86 & 811 & 5 & 4. 34 \\
\hline & \multirow{2}{*}{3} & $N$ & 233 & 200 & 85.84 & 872 & 9 & 3.74 \\
\hline & & $\mathrm{S}$ & 202 & 180 & 89.10 & 705 & 11 & 3.49 \\
\hline & \multirow[b]{2}{*}{5} & $N$ & 149 & 143 & 95.97 & 790 & 5 & 5.30 \\
\hline & & $\mathrm{S}$ & 208 & $18 i$ & 89.90 & 831 & 8 & 4.00 \\
\hline & \multirow[b]{2}{*}{6} & $\mathrm{~N}$ & 136 & 131 & 96.32 & 679 & 3 & 5.00 \\
\hline & & $\mathrm{S}$ & 133 & 116 & 87.22 & 491 & 6 & 3.69 \\
\hline & \multirow{2}{*}{8} & $\mathrm{~N}$ & 253 & 226 & 89.33 & 1132 & 2 & 4. 47 \\
\hline & & $S$ & 215 & 204 & 94.88 & 938 & 3 & 4. 36 \\
\hline & \multirow{2}{*}{9} & $N$ & 179 & 176 & 98.32 & 989 & 3 & 5.53 \\
\hline & & $\mathrm{S}$ & 163 & 140 & 85.88 & 675 & 9 & 4. 14 \\
\hline & \multirow{2}{*}{10} & $N$ & 188 & 145 & 77.13 & 653 & 10 & 3.47 \\
\hline & & $\mathrm{S}$ & 170 & 151 & 88.82 & 658 & 4 & 3.87 \\
\hline
\end{tabular}

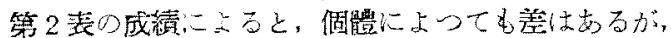

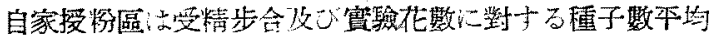

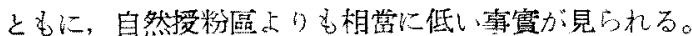

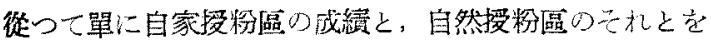

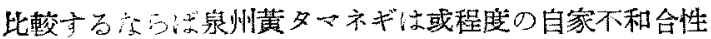
を有するよ５に考之られる。然し自家授粉區の成續と， 異株授粉區のニれとを比較すると，其の稳度は個體によ つても違つているが，概して言えば大差なく，航つて自

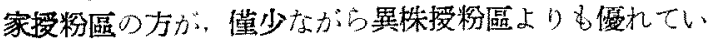

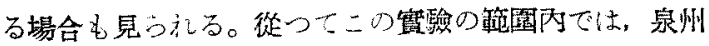
黄タマネギは自家和合植物と考うぐきるのであらう。
第 2 表タマ・ギの自诼受精力

\begin{tabular}{|c|c|c|c|c|c|c|c|c|}
\hline 馡次 & $\mid$ & 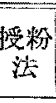 & $\begin{array}{l}\text { 算驗 } \\
\text { 花教 }\end{array}$ & $\begin{array}{l}\text { 愛精 } \\
\text { 拒数 }\end{array}$ & $\begin{array}{l}\text { 受精 } \\
\text { 步合 } \\
(\%)\end{array}$ & $\begin{array}{l}\text { 種子 } \\
\text { 總数 }\end{array}$ & $\mid \begin{array}{l}\text { 不完 } \\
\text { 全種 } \\
\text { 数 }\end{array}$ & 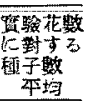 \\
\hline & 2 & $\begin{array}{l}\mathrm{N} \\
\mathrm{S} \\
\mathrm{C}\end{array}$ & $\begin{array}{l}402 \\
314 \\
325\end{array}$ & $\begin{array}{l}207 \\
136 \\
140\end{array}$ & $\begin{array}{l}51.44 \\
43.31 \\
43.08\end{array}$ & $\begin{array}{l}732 \\
324 \\
333\end{array}$ & $\begin{array}{l}5 \\
2 \\
3\end{array}$ & $\begin{array}{l}1.83 \\
1.03 \\
1.02\end{array}$ \\
\hline & 4 & $\begin{array}{l}\mathrm{N} \\
\mathrm{S} \\
\mathrm{C}\end{array}$ & $\begin{array}{l}436 \\
335 \\
355\end{array}$ & $\begin{array}{r}375 \\
40 \\
41\end{array}$ & $\begin{array}{l}86.01 \\
11.94 \\
11.55\end{array}$ & $\begin{array}{r}768 \\
52 \\
58\end{array}$ & $\begin{array}{l}5 \\
0 \\
0\end{array}$ & $\begin{array}{l}1.76 \\
0.16 \\
0.16\end{array}$ \\
\hline & 5 & $\begin{array}{l}N \\
S \\
C\end{array}$ & $\begin{array}{l}359 \\
358 \\
366\end{array}$ & $\begin{array}{r}144 \\
97 \\
90\end{array}$ & $\begin{array}{l}40.11 \\
27.09 \\
24.59\end{array}$ & $\begin{array}{r}506 \\
260 \\
-\quad 245\end{array}$ & $\begin{array}{l}3 \\
1 \\
0\end{array}$ & $\begin{array}{l}1.41 \\
0.73 \\
0.67\end{array}$ \\
\hline & 6 & $\begin{array}{l}\mathrm{N} \\
\mathrm{S} \\
\mathrm{C}\end{array}$ & $\begin{array}{l}415 \\
337 \\
325\end{array}$ & $\begin{array}{r}109 \\
59 \\
60\end{array}$ & $\begin{array}{l}26.26 \\
17.51 \\
18.46\end{array}$ & $\begin{array}{l}314 \\
117 \\
123\end{array}$ & $\begin{array}{l}1 \\
1 \\
1\end{array}$ & $\begin{array}{l}0.76 \\
0.35 \\
0.38\end{array}$ \\
\hline 1944 & 7 & $\begin{array}{l}\mathrm{N} \\
\mathrm{S} \\
\mathrm{C}\end{array}$ & $\begin{array}{l}385 \\
255 \\
285\end{array}$ & $\begin{array}{r}291 \\
69 \\
66\end{array}$ & $\begin{array}{l}75.58 \\
27.06 \\
23.16\end{array}$ & $\begin{array}{l}862 \\
125 \\
113\end{array}$ & $\begin{array}{r}10 \\
2 \\
2\end{array}$ & $\begin{array}{l}2.24 \\
0.49 \\
0.40\end{array}$ \\
\hline * & 8 & $\begin{array}{l}\mathrm{N} \\
\mathrm{S} \\
\mathrm{C}\end{array}$ & $\begin{array}{l}382 \\
220 \\
311\end{array}$ & $\begin{array}{r}313 \\
88 \\
95\end{array}$ & $\begin{array}{l}81.94 \\
40.00 \\
30.55\end{array}$ & $\begin{array}{r}1187 \\
210 \\
249\end{array}$ & $\begin{array}{l}4 \\
0 \\
2\end{array}$ & $\begin{array}{l}3.11 \\
0.95 \\
0.80\end{array}$ \\
\hline & 9 & $\begin{array}{l}\mathrm{N} \\
\mathrm{S} \\
\mathrm{C}\end{array}$ & $\begin{array}{l}456 \\
280 \\
320\end{array}$ & $\begin{array}{l}364 \\
168 \\
178\end{array}$ & $\begin{array}{l}79.82 \\
60.00 \\
55.63\end{array}$ & $\begin{array}{r}1287 \\
409 \\
446\end{array}$ & $\begin{array}{r}10 \\
2 \\
2\end{array}$ & $\begin{array}{l}2.82 \\
1.46 \\
1.39\end{array}$ \\
\hline & 10 & $\begin{array}{l}\mathrm{N} \\
\mathrm{S} \\
\mathrm{C}\end{array}$ & $\begin{array}{l}441 \\
443 \\
459\end{array}$ & $\begin{array}{l}328 \\
195 \\
180\end{array}$ & $\begin{array}{l}74.38 \\
44.02 \\
39.22\end{array}$ & $\begin{array}{l}872 \\
439 \\
412\end{array}$ & $\begin{array}{l}1 \\
1 \\
1\end{array}$ & $\begin{array}{l}1.98 \\
0.99 \\
0.90\end{array}$ \\
\hline \multirow{8}{*}{1946} & 1 & $\begin{array}{l}N \\
S\end{array}$ & $\begin{array}{l}518 \\
329\end{array}$ & $\begin{array}{l}455 \\
125\end{array}$ & $\begin{array}{l}87.84 \\
38.00\end{array}$ & $\begin{array}{r}1290 \\
263\end{array}$ & $\begin{array}{r}37 \\
2\end{array}$ & $\begin{array}{l}2.49 \\
0.80\end{array}$ \\
\hline & 2 & $\begin{array}{l}N \\
S\end{array}$ & $\begin{array}{l}234 \\
349\end{array}$ & $\begin{array}{l}231 \\
229\end{array}$ & $\begin{array}{l}98.71 \\
65.61\end{array}$ & $\begin{array}{l}784 \\
467\end{array}$ & $\begin{array}{r}7 \\
15\end{array}$ & $\begin{array}{l}3.55 \\
1.34\end{array}$ \\
\hline & 4 & $\begin{array}{l}N \\
S\end{array}$ & $\begin{array}{l}276 \\
243\end{array}$ & $\begin{array}{l}264 \\
109\end{array}$ & $\begin{array}{l}95.65 \\
44.85\end{array}$ & $\begin{array}{l}962 \\
254\end{array}$ & $\frac{2}{3}$ & $\begin{array}{l}3.49 \\
1.05\end{array}$ \\
\hline & 5 & $\begin{array}{l}N \\
S\end{array}$ & $\begin{array}{l}355 \\
260\end{array}$ & $\begin{array}{l}270 \\
103\end{array}$ & $\begin{array}{l}76.06 \\
39.61\end{array}$ & $\begin{array}{l}811 \\
256\end{array}$ & $\begin{array}{l}6 \\
2\end{array}$ & $\begin{array}{l}2.28 \\
0.98\end{array}$ \\
\hline & 7 & $\begin{array}{l}\mathrm{N} \\
\mathrm{S}\end{array}$ & $\begin{array}{l}460 \\
271\end{array}$ & $\begin{array}{l}323 \\
129\end{array}$ & $\begin{array}{l}70.21 \\
47.60\end{array}$ & $\begin{array}{l}813 \\
229\end{array}$ & $\begin{array}{l}3 \\
1\end{array}$ & $\begin{array}{l}1.77 \\
0.85\end{array}$ \\
\hline & 8 & $\begin{array}{l}N \\
S\end{array}$ & $\begin{array}{l}248 \\
169\end{array}$ & $\begin{array}{r}207 \\
66\end{array}$ & $\begin{array}{l}83.47 \\
39.05\end{array}$ & $\begin{array}{l}808 \\
156\end{array}$ & $\begin{array}{l}2 \\
1\end{array}$ & $\begin{array}{l}3.26 \\
0.92\end{array}$ \\
\hline & 9 & $\begin{array}{l}N \\
S\end{array}$ & $\begin{array}{l}529 \\
436\end{array}$ & $\begin{array}{l}424 \\
157\end{array}$ & $\begin{array}{l}80.15 \\
36.01\end{array}$ & $\begin{array}{l}825 \\
273\end{array}$ & $\begin{array}{l}1 \\
1\end{array}$ & $\begin{array}{l}1.56 \\
0.63\end{array}$ \\
\hline & 10 & $\begin{array}{l}N \\
S\end{array}$ & $\begin{array}{l}583 \\
423\end{array}$ & $\begin{array}{l}535 \\
189\end{array}$ & $\begin{array}{l}91.76 \\
44.68\end{array}$ & $\begin{array}{r}1358 \\
334\end{array}$ & $\begin{array}{r}11 \\
4\end{array}$ & $\begin{array}{l}2.33 \\
0.79\end{array}$ \\
\hline \multirow{3}{*}{1948} & 1 & $\begin{array}{l}\mathrm{N} \\
\mathrm{S} \\
\mathrm{C}\end{array}$ & $\begin{array}{r}1245 \\
742 \\
757\end{array}$ & $\begin{array}{l}938 \\
170 \\
116\end{array}$ & $\begin{array}{l}75.34 \\
22.91 \\
15.32\end{array}$ & $\begin{array}{r}1964 \\
318 \\
151\end{array}$ & $\begin{array}{r}19 \\
2 \\
7\end{array}$ & $\begin{array}{l}1.58 \\
0.43 \\
0.20\end{array}$ \\
\hline & 2 & $\begin{array}{l}\mathrm{N} \\
\mathrm{S} \\
\mathrm{C}\end{array}$ & $\begin{array}{l}1231 \\
1151 \\
1392\end{array}$ & $\begin{array}{l}782 \\
162 \\
126\end{array}$ & $\begin{array}{r}63.52 \\
14.07 \\
9.05\end{array}$ & $\begin{array}{r}1438 \\
269 \\
234\end{array}$ & $\begin{array}{r}32 \\
3 \\
3\end{array}$ & $\begin{array}{l}1.17 \\
0.23 \\
0.17\end{array}$ \\
\hline & 5 & $\begin{array}{l}\mathrm{N} \\
\mathrm{S} \\
\mathrm{C}\end{array}$ & $\begin{array}{l}1162 \\
1059 \\
1041\end{array}$ & $\begin{array}{r}550 \\
57 \\
76\end{array}$ & $\begin{array}{r}47.33 \\
5.83 \\
7.30\end{array}$ & $\begin{array}{r}1295 \\
91 \\
131\end{array}$ & $\begin{array}{r}32 \\
2 \\
1\end{array}$ & $\begin{array}{l}1.11 \\
0.09 \\
0.13\end{array}$ \\
\hline
\end{tabular}

\section{考察}

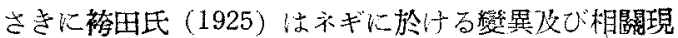
象に閣与る報文中に於て，筫酸成績は別に上げていない が，下のよ5に報告している。即ちネギは單に被裚す、る 


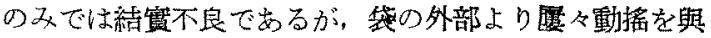

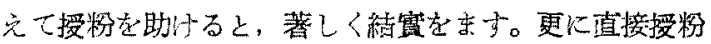

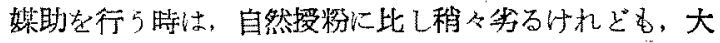
差和き維實を見るという。土屋氏（1928）の九條ネギに

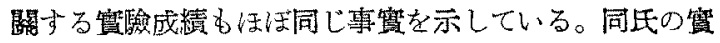
䛗成績を檢討すると，其の稔性は自家授粉よりも多少異 株授粉の力が高々，自然授㘼は更に高くなつている。上 記筆者の九攸ネギについてての察驗成績では，自然授粉，

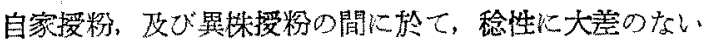
結果を示している。之等の成續によれば，九條ネギが自 家和合䐈物であるこ之は確實である。

DARWIN 氏（1876）によると，ターネギは自然狀態に

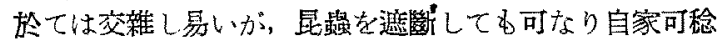
性を示すと報じている。夷に KoTOWSKI 氏 (1926) の タマネギに關する論交は，原著を見ることは出來なかつ たが，原著者の自抄によると，品杼 Zittauer は高度に

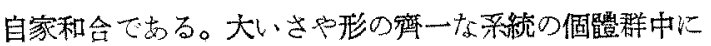
於ては，遗傳的な自家和合性の變異が見出された。郎七 その個體群中には，遺傳的に自家和合性の高いるのと， 低い：もとが混在していだとい。土屋氏（1928）の夕

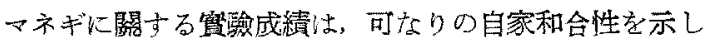

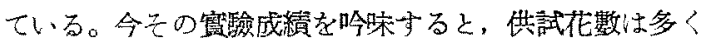
ないが，自家授粉の稳性が却つて他家授粉のそれ上り。 高くなつている。最近千石氏 (1946) は，黄タマネギを

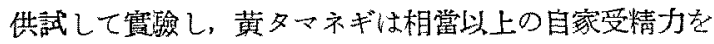
示するのであり，自家授粉の稔性は却つて他家授㸮の乞 れよりも高いと報告した。上泼の篗者の富驗成績も之等 とよく一致し，個體によつても差はちるが，泉州璌タ、 ネギは可なりの自家受精力を有し；自家授粉區は多少異 株授粉區よりも高、稔性を示奇場合がるるようである。 從つて泉州翼タ、ホギは自家和合植物でらう。

夯に自然授粉區之人工授枌區（自家授枌區支び異株授 粉區）との間に其の稔性に閣して相當の差珙のもる理由

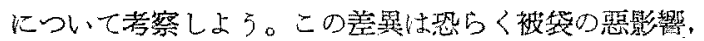

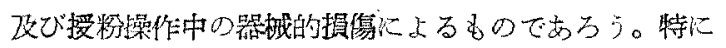

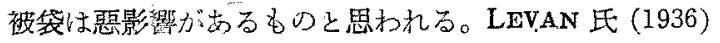
の報ずるところによると，エゾネギ（Allium Sehoenoprasum)の $4 \mathrm{x} \times 2 \mathrm{x}$ の $\mathrm{F}_{1}$ に於ては，被篹せるものは 完全に自家不稔であつたが，自然開花させた場合には極 わて多卙の種子が得られた。同 $\mathrm{F}_{2}$ に於ても被袋隔離し た埸合には，種子のとまりが惡かつた。よく調べてみる と笠の中炕は，菌類の發生其の他加認められたので，被 华は留影響があるものと考えられるという。前記千 石氏 (1946) b办被笠の惡影響を注意している。とこる
が筆者の九條ネギの成績では，被袋の惡い影響は族ど見

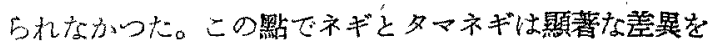
示するのとい占ら。

JONES 爫び EMSWELLER 兩氏 (1934) によると， タ マネギの品種 Stockton Yellow Globe, 双び Australian

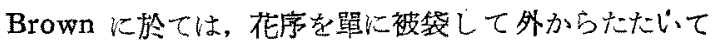

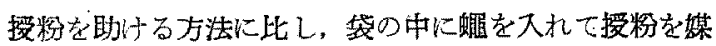
助させると，大繁自殖種子の收昷を俖加した。その場合

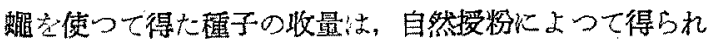
たものに近かつたいう。從つてタマネギの自家受精力 は，被袋及び授粉法の改善によつて一層高得るものと 考完られる。

份筆者のタマネギに關する算䛗成績中，1944 年及び 1946 年の稔性汇比して, 1948 年の稔性が低からた。この 亨管は前雨年に於ける筫驗は硝子室內で施行したのに， 1948 年は露地の不完全なトタン板の屋根の下で行つた ので，多少雨にあたつた第ではないかと考克られる。タ

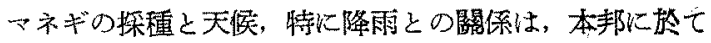

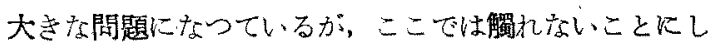
上5。

\section{摘 要}

1）九條ネギは自家和合植物である。

2）泉州黃タマネギは自家和合植物であらう。自家授 粉の稔性が自然授粉のそれに比して可なりに低いのは，

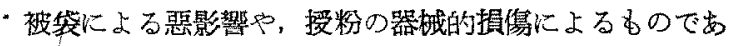
万弓。

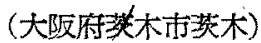

\section{引.用文獻}

DARWIN, C., 1876 : The effects of cross and self fertilization in the vegetable kingdom, London.

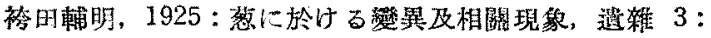
$83-100$.

JoNES, H. A. and EMsweller, S. L., 1934: The use of flies as onion pollinators: Proc. Amer. Soc. Hort. Sci., 31: 160-164.

Kotowski, F., 1926 : The efficiency of self-and cross fertility in the onion. Acta. Soc. Bot. Poloniae 4 (Suppl.) : 11-16. (Ref. Biol. Abst., 3: 411, 1929.)

LEVAN, A., 1936 : Zytologische Studien an Allium Schoenoprasum. Hereditas., 22: 1-128.

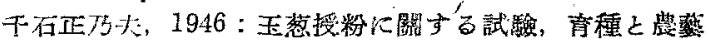
$1: 268-271$.

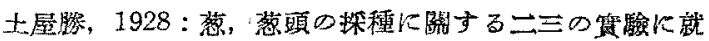
て, 图瑟它研究 23: 47-61. 